\title{
Research on Evaluation for Sustainable Development of Energy Economy in Hebei Province
}

\author{
Hai-ning Bai \\ Department of Economic Management, North China Electric Power University,Baoding, China
}

\begin{abstract}
Based on the sustainable development theory of energy economy,this paper constructs the evaluation system of sustained development of energy economy considering the following four sub-systems: the sustainable development of energy usage, environment protection, economy and society. Based on this system,it evaluates the sustainable development level of energy economy in Hebei province during 2008 to 2014, and compares the situation of Hebei with the average level of nation.
\end{abstract}

Keywords: Energy economy; Sustainable development; Energy consumption; energy demand; Energy utilizing; Regional economy

\section{Introduction}

Energy is not only closely related to the economic and social development, but also the important factor affecting the international politics, military and diplomacy. In the modern industrial production, energy is the main source of power, and it is the important material basis for the sustainable development of the economy and society. At present, China is in the rapid development of the national economy, the development of industrial and agricultural production is largely limited by the shortage of energy. And, as the population continues to grow, the demand for energy is increasing ${ }^{[1]}$.

Hebei province, whose the energy resources endowment is good and the energy variety is complete, is the energy production big province, and simultaneously is the energy consumption province. As China's important energy and basic industrial base, Hebei province has an advantage in coal and other aspects of natural resources, and has also made tremendous achievements in energy industry. However, Hebei Province belongs to the energy input province. The industrial structure of energy consumption is irrational, the power generation investment based on coal is too large. Thus, it is necessary to realize that the achievements of Hebei province are mainly rely on large consumption of energy resources in the extensive mode of development. The extensive mode of development makes originally the shortage of energy resources and fragile ecological environment is facing greater pressure. And the rapid development of economy supported by this mode also won't last long. Therefore, the Hebei province should vigorously develop renewable energy, develop nuclear energy and coal conversion and clean technology, adjust the economic structure to achieve energy security and sustainable development.

\section{The theory of energy economy and sustainable development}

Energy economy and its sustainable development are the core of energy economics. Energy economy refers to the sum of the energy of various types of industrial economy, and is an important part of the national economy, specifically, refers to those that produce the energy of the material production, exchange, distribution and consumption of economic activity. Sustainable development is a new concept of development, which emphasizes the comprehensive coordinated development of population, economy, resources and environment.

The sustainable development of energy economy refers to the development of energy not only meeting the needs of economic development, and not causing intolerable damage to the human survival environment and 
ecological health and life. It not only satisfies the current needs of energy, and do not cause bad influence and even pose a hazard to meet the needs the ability of future generations. Therefore, sustainable development of energy economy includes not only first energy development, transportation, processing, transformation, distribution and usage, but also is an complex system which regards economic factors, social factors and ecological factors as the important part of $\mathrm{it}^{[2]}$.

\section{The evaluation system of sustainable development of energy economy}

According to the characteristics of the energy economy, concerning the coordinated development of energy, economy and society, the evaluation system of sustainable development of energy economy can be made up by the sustainable development of energy utilization, the sustainable development of environment, the sustainable development of economy and the sustainable development of society. Every sub evaluation system includes several evaluation indexes. The core evaluation index and the evaluation criteria of the sub evaluation system are as follows ${ }^{[3]}$ :

(1) The sustainable development of energy utilization. In order to achieve the the sustainable development of energy utilization, the efficiency of energy utilization should be increased. Namely, the change rate of the energy consumption per unit of GDP is less than zero.

$$
\begin{gathered}
r_{1}=\Delta R_{1} / R_{10}<0 \\
\Delta R_{1}=R_{1}-R_{10}
\end{gathered}
$$

Where, $r_{1}$ represents the rate of energy consumption per unit of GDP; $R_{1}$ represents the energy consumption per unit of GDP in evaluation system; $R_{10}$ represents the energy consumption per unit of GDP in referring system; $\Delta R_{1}$ represents the energy consumption changes per unit of GDP.

(2) The sustainable development of environment. In order to ensure the sustainable development of the environment, the pollution caused by the waste gas emission of unit industrial GDP should not increase.

$$
r_{2}=\Delta R_{2} / R_{20}<0
$$

$$
\Delta R_{2}=R_{2}-R_{20}
$$

Where, $r_{2}$ represents the change rate of waste gas emissions of unit industrial GDP; $R_{2}$ represents the waste gas emissions of unit industrial GDP in evaluation system; $R_{20}$ represents the waste gas emissions of unit industrial GDP in referring system; $\Delta R_{2}$ represents the changes of waste gas emissions of unit industrial GDP.

(3) The sustainable development of economy. In order to achieve sustainable development of economy, the elasticity coefficient of energy consumption is less than 1 and its change is less than zero.

$$
\begin{gathered}
R_{3}<1 \\
\Delta R_{3}=R_{3}-R_{30}<0
\end{gathered}
$$

Where, $R_{3}$ represents the elasticity coefficient of energy consumption in evaluation system; $R_{30}$ represents the elasticity coefficient of energy consumption in referring system; $\Delta R_{3}$ represents the changes of elasticity coefficient of energy consumption.

(4) The sustainable development of society. In order to achieve the sustainable development of society, the change rate of per capita energy amount is more than zero.

$$
\begin{gathered}
r_{4}=\Delta R_{4} / R_{40}>0 \\
\Delta R_{4}=R_{4}-R_{40}
\end{gathered}
$$

Where, $r_{4}$ represents the change rate of per capita energy amount; $R_{4}$ represents per capita energy amount in evaluation system; $R_{40}$ represents per capita energy amount in referring system; $\Delta R_{4}$ represents the changes of per capita energy amount.

\section{The evaluation of sustainable development of energy economy in Hebei province}

Considering the changes in the concept of energy consumption and economic and social development of stability and continuity in our country, this paper selects data in 2008 as the basic frame of reference, regard 2011 as the transition period, select the data in 2014 as the final evaluation system. Evaluate the state of sustainable development of energy economy in Hebei province and compare it of the national average level. The relevant evaluation index data are shown in Table 1. 
Table 1. The relevant evaluation index data

\begin{tabular}{ccccccc}
\hline \multirow{2}{*}{ Index } & \multicolumn{3}{c}{ Hebei province } & \multicolumn{3}{c}{ National average level } \\
& 2008 & 2011 & 2014 & 2008 & 2011 & 2014 \\
\hline $\begin{array}{c}\text { Industrial emissions } \\
\text { Energy consumption } \\
\text { elasticity coefficient }\end{array}$ & 15768 & 39254 & 50779 & 198906 & 330992 & 436064 \\
$\quad$ Total population & 6769 & 6898 & 7034 & 129227 & 131448 & 133474 \\
Coal basic reserves & 89.0 & 68.2 & 56.3 & 3342 & 3335 & 3190 \\
$\quad \begin{array}{c}\text { Total energy } \\
\text { consumption }\end{array}$ & 15279 & 21690 & 28266 & 174990 & 246270 & 306647 \\
$\quad$ GDP & 6921 & 11660 & 17235 & 135822 & 210871 & 340506 \\
$\quad \begin{array}{c}\text { Industrial GDP } \\
\text { Unit GDP energy } \\
\text { consumption }\end{array}$ & 3212 & 5490 & 7983 & 54946 & 91311 & 135240 \\
$\begin{array}{c}\text { Unit Industrial GDP } \\
\text { emissions }\end{array}$ & 4.91 & 1.86 & 1.64 & 1.29 & 1.17 & 0.90 \\
$\begin{array}{c}\text { Per capita energy } \\
\text { amount }\end{array}$ & 131 & 9.15 & 6.36 & 3.62 & 3.62 & 3.22 \\
\hline
\end{tabular}

(1) The evaluation of energy utilization. Compared with 2011, the $r_{1}$ of Hebei province in 2014 was $-11.83 \%$, which is below 0 . At the same period, the national average level is $-23.08 \%$. It can conclude that compared with 2011, the energy utilization efficiency of Hebei province in 2014 is improved to some extent, but compared with the national average level at the same period, the improvement was significantly lower than the national average.

(2) The evaluation of environment. Compared with 2011, the $r_{2}$ of Hebei province in 2014 was $-11.04 \%$, which is below 0 . At the same period, the national average level is $-11.05 \%$. It shows that, compared with 2011, the waste gas emissions of unit industrial GDP reduced, and kept the same level compared with the national average level, which is in favor of environmental sustainable development. But in 2008, this value increased, so the situation of environment pollution in Hebei province has yet to be further improved.

(3) The evaluation of economy. Compared with 2011, the $R_{3}$ of Hebei province in 2014 was 1.67, which is above 0 . And $\Delta R_{3}$ is -0.3 , which is below 0 . Similarly, compared with 2008, the energy consumption elasticity coefficient of 2011 in Hebei province and the whole country can be calculated, which are respectively -0.66 and -0.47 . These data indicate that Hebei province failed to reverse the economic growth which depends on a lot of energy consumption situation. The extensive mode of economic development has not been changed, which is not conducive to the realization of the sustainable development of economy.

(4) The evaluation of of society. Compared with 2011, the $r_{4}$ of Hebei province in 2014 was $-19.04 \%$, which is below 0 . At the same period, the national average level is $-5.81 \%$. Compared with 2011 , the change rate of per capita amount in 2014 is less than 0, which indicates that with the increasing efficiency of energy usage, the per capita amount of energy do not increase, which is conducive to social sustainable development. At the same period, this value of national average level is also less than 0 , which shows that the national per capita energy physical quantity also declines, but the decline speed is not faster than that of Hebei province. 


\section{CONCLUSIONS}

In a word, the sustainable development of energy economy in Hebei province still should deeply improve. We should implement the scientific concept of development, and maintain the sustainable economic development of the high degree of perseverance to do a good job of energy-saving.

\section{Acknowledgments}

This study was supported by the Fundamental Researc h Funds for the Central Universities (Project ID:13ZD21)

\section{References}

[1] Li Zhe, Shen Xiaoliu, Shen Yangshuo, Tan Zhongfu, "Beijing Energy Economic Environmental Assessment for Sustainable Development," Power and Energy, pp. 264-267, 2011.

[2] Liu Aiqin, "Evaluation on Sustained Development of Energy Economy in Shandong Province," Technology Economics, pp. 78-83, 2008.

[3] Ding Zhanwen, Tian Lixin, Yang Honglin, "A Game on Sustainable Development in Eastern-Western Energy Economy," Mathematics in Practice and Theory, pp. 29-35, 2005. 